\title{
PELATIHANJURNALIS WARGA DI RPTRA BAUNG MENGAJAK ANAK BELAJAR MENJADI AGEN INFORMASI
}

\author{
Dewi Lisa Nehemia ${ }^{1)}$, Silmi Kaffah Andriani'), Yayu Sriwartini ${ }^{3)}$
}

Ilmu Komunikasi, FISIP, Universitas Nasional

\begin{abstract}
Abstrak
Artikel ini adalah hasil dari kegiatan pengabdian kepada masyarakatyakni Citizen Journalism yang bertujuan untuk memberikan edukasi kepada anak-anak Ruang Publik Terpadu Ramah Anak (RPTRA) Baung, Jakarta Selatan tentang pengetahuan dasar jurnalistik dan jurnalis warga. Dilatarbelakangi atas kepedulian terhadap generasi muda yang saat ini sedang kecanduan internet, media sosial dan tidak sedikit juga yang terpengaruh oleh berita hoax. Metode pelaksanaan dengan melakukan pelatihan tentang citizen journalism baik secara teori maupun praktis. Harapan dari kegiatan pengabdian kepada masyarakat citizen journalismmemupuk budaya menulis, membentuk generasi muda menjadi generasi yang bijak dalam penggunaan internet dan media sosial, sehingga mereka dapat menjadi agen informasi penyebar berita yang positif dan akurat bukan berita bohong. Sehingga generasi muda bisa menjadi mata dan telinga bagi lingkungan dimana mereka tinggal.
\end{abstract}

Keywords: jurnalis warga, rptra baung, jurnalis anak, agen informasi

\begin{abstract}
This article is the result of community service activities namely Citizen Journalism, to provide education for children. Child Friendly Integrated Public Space (RPTRA) of Baung, South Jakarta about basic knowledge of journalism and citizen journalism. Motivated by the concern for young people who are currently addicted to the internet, social media and also affected by hoax news. The method of implementation is by conducting training on citizen journalism both theoretically and practically. Expectations from community service activities for citizen journalism foster a culture of writing, shaping the younger generation into a wise generation in the use of the internet and social media, so that theybecome the agents of information disseminating positive and accurate news not fake news. So the young generation can be the eye and ear of the environment in which they live.
\end{abstract}

Keywords: citizen journalism, rptra baung, journalist kids, information agent

Correspondence author: Dewi Lisa Nehemia, dewielisa.88@gmail.com, Jakarta, and Indonesia

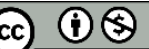

This work is licensed under a $C C-B Y-N C$

\section{PENDAHULUAN}

Era globalisasi dan keterbukaan informasi sudah semakin berkembang. Salah satunya adalah teknologi internet. Internet dijelaskan sebagai kumpulan yang luas dari jaringan komputer besar dan kecil yang saling berhubungan menggunakan jaringan komunikasi yang ada di seluruh dunia. Kemunculan internet yang merupakan jaringan komputer yang memungkinkan terjadinya pertukaran informasi tanpa hambatan menjadi sebuah media baru bagi masyarakat. Hal ini memberikan peluang bagi mereka yang non 
jurnalis untuk melakukan publikasi, pandangan, pendapat, informasi serta berpartisipasi menjadi Citizen Journalism. Citizen Journalism atau Jurnalis Warga adalah suatu bentuk kegiatan jurnalisme yang dilakukan oleh warga biasa. Warga biasa yang dimaksud adalah warga yang bukan berprofesi sebagai jurnalis profesional. Jadi, Citizen Journalism adalah seorang warga biasa, tanpa harus berlatar belakang Pendidikan jurnalistik atau ilmu kewartawanan, dapat melakukan kegiatan jurnalisme dan menyampaikan berita dengan gayanya sendiri (Kusumaningati, 2012:5).Warga dapat menuliskan pandangannya atas suatu peristiwa karena didorong oleh keinginan untuk membagi apa yang dilihat dan diketahuinya.

Dewasa ini tidak hanya orang dewasa, namun remaja bahkan anak kecil juga menggunakan telepon pintar untuk bertukar informasi. Selain untuk kepentingan berkomunikasi juga dimanfaatkan untuk media sosial baik secara positif maupun negatif. Dalam melakukan akses ke media sosial tentunya memerlukan internet. Tidak dapat dipungkiri, internet dengan segala informasi yang ada didalamnya, kerap menawarkan hal-hal yang menggiurkan, yang kadang menyimpang dari etika dan moral. Mulai dari konten yang menampilkan adegan kekerasan, pornografi hingga pornoaksi.

Dalam penggunaan internet, kita harus bisa menyaring mana informasi yang layak dikonsumsi dan tidak, informasi yang akurat dan dapat dipertanggungjawabkan kebenarannya atau informasi yang tidak sesuai dengan fakta (hoax). Hoax merupakan informasi atau berita yang berisi hal-hal yang belum pasti atau yang benar-benar bukan merupakan fakta yang terjadi. Media sosial seringkali menjadi tempat penyebaran informasi. Selain mudah, media sosial juga memiliki jutaan pengguna sehingga informasi yang disiarkan dapat langsung dijangkau oleh pengguna lainnya.

Penetrasi media sosial telah mengalahkan media massa lainnya seperti media cetak, dan media elektronik atau lainnya. Berdasarkan survey Asosiasi Penyedia Jasa Internet Indonesia (APJII) tahun 2018, jumlah pengguna internet di Indonesia 171.17 juta jiwa dari 264.16 juta jiwa atau 64.8 persen dari total populasi Indonesia. Sedangkan Pulau Jawa memiliki kontribusi tertinggi pengguna internet sebesar 55.7\% dengan $80.4 \%$ pengguna internet dari provinsi Jakarta. Penggunaan media sosial oleh pengguna internet menjadi alasan kedua sebesar $19.1 \%$ dalam menggunakan internet selain untuk berkomunikasi. Hal ini membuktikan bahwa penggunaan media sosial sebagai sebuah produk teknologi informasi dan komunikasi memang tidak terelakkan. Anggapan bahwa "media sosial semakin tak terelakkan" bisa dianggap sebagai konstruksi sosial. Jika hari ini orang semakin merasa tak bisa melepaskan diri dari media sosial, sebetulnya berangkat dari orang yang bersangkutan memaknai perangkat atau aplikasi tersebut. Anggapananggapan yang berkembang ditengah-tengah masyarakat itulah yang pada akhirnya mempengaruhi sikap individu (Stark, Fins, \& Stark, 2012).

Media sosial menjadi sarana yang efektif dan efisien dalam menyampaikan suatu informasi kepada khalayak serta memiliki peran penting sebagai agen perubahan dan pembaharuan. Media Sosial telah menjadi kunci untuk memprovokasi pemikiran, pendapat, dan tindakan seputar isu-isu sosial. Menurut pernyataan Carr dan Hayes (2015) dimana media sosial adalah media berbasis internet yang memungkinkan pengguna berkesempatan untuk berinteraksi dan mempresentasikan diri, baik secara seketika ataupun tertunda, dengan khalayak luas maupun tidak yang mendorong nilai dari usergenerated content dan persepsi interaksi dengan orang lain.

Pada era majunya teknologi dan keterbukaan informasi ini media sosial mempunyai peranan strategis sebagai saranan transformasi informasi juga sarana komunikasi antar sesama masyarakat maupun antara masyarakat dengan pemerintah dalam menyampaikan 
keluhan maupun berbagai aspirasi. Media sosial menjadi media baru bagi para jurnalisme warga untuk melakukan kegiatan jurnalistiknya. Keberadaan Citizen Journalism menjadi sangat penting ditengah keterbatasan dalam menggali informasi terupdate yang terdapat di pelosok daerah dan menjadi media untuk mengaktualisasikan diri sebagai agen informasi yang dapat bermanfaat bagi lingkungan sekitar dan banyak orang. Dengan memanfaatkan peralatan teknologi modern dan internet, kita dapat berkreasi melengkapi fakta maupun memeriksa fakta-fakta yang diberitakan oleh media.

Citizen Journalism sangat penting untuk generasi muda terutama anak-anak karena dapat melatih anak-anak untuk lebih melek media, dan lebih peka serta peduli terhadap lingkungan sekitar. Citizen Journalism mengajak anak-anak untuk menjadi bagian dari agen perubahan serta berperan aktif dalam menjadi agen informasi.

Berdasarkan latar belakang inilah, tim pengabdian kepada masyarakat, Program Studi Ilmu Komunikasi, Fakultas Ilmu Sosial dan Ilmu Politik, Universitas Nasional melakukan kegiatan pengabdian masyarakat dengan tema Citizen Journalism:Menjadi Mata dan Telinga bagi Lingkungan. Kegiatan pengabdian kepada masyarakat ini bertujuan untuk melatih kepercayadirian serta kemampuan jurnalistik kepada anak-anak di lingkungan Ruang Publik Terpadu Ramah Anak (RPTRA) Baung, Jakarta Selatan. Melalui kegiatan pengabdian masyarakat ini, anak-anak akan menambah pengetahuan dan wawasan tentang apa itu citizen journalism, bagaimana sebuah informasi diproduksi hingga menjadi sebuah berita yang dapat dikonsumsi. Selain itu, anak-anak dapat mengasah keterampilan menulis dan minat baca, mempertajam kemampuan berekspresi, dan kemampuan mendengarkan serta bercerita.

Dengan memberikan stimulasi kepada anak-anak untuk mendalami secara lebih jauh sebuah kejadian yang mereka lihat, mereka dengar di sekitar lingkungan mereka tinggal diharapkan dapat menjadi penyambung informasi yang akurat dan memotong rantai berita hoax. Citizen Journalism: Menjadi Mata dan Telinga bagi Lingkungan memberikan pelatihan pada anak-anak untuk belajar lebih peka terhadap lingkungan, dan bagaimana mendapatkan, mengelola serta menyebarkan informasi.

\section{METODE PELAKSANAAN}

Metode pelaksanaan pada program pengabdian masyarakat Citizen Journalism diadakan di Ruang Publik Terpadu Ramah Anak (RPTRA) Baung, yang beralamat di Jl. Baung 3, Rt. 04/Rw. 02, Kebagusan, Kec. Pasar Minggu, Jakarta Selatan 12520 pada hari Minggu, 22 Desember 2019 pukul 11.00 - 12.00 WIB dengan memberikan informasi pengenalan dan pemahaman sederhana tentang citizen journalism. Kegiatan pengabdian kepada masayarakat ini diikuti oleh kurang lebih 20 orang anak-anak berumur $6-15$ tahun dan dilaksanakan dalam beberapa tahap, yaitu:

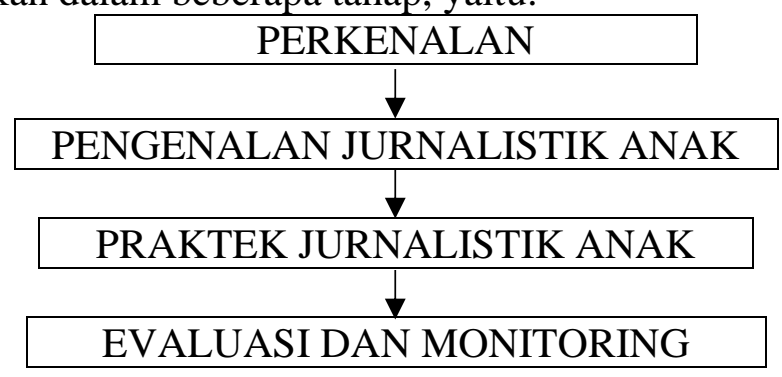

Gambar 1. Tahapan pelaksanaan kegiatan pengabdian kepada masyarakat dengan tema Citizen Journalism. 
Perkenalan sebagai tahap pertama merupakan tahap pembuka untuk menjalin kedekatan antara anak-anak dan tim pelaksana. Mengamati potensi setiap anak, dan menggali minat menulis dan membaca melalui pengenalan diri serta menceritakan pengalaman yang berkesan. Dengan mengetahui informasi tersebut, anak-anak diminta untuk berbagi pengalaman dan pengetahuannya hingga bisa mengolahnya menjadi sebuah berita.

Pengenalan jurnalistik anak sebagai tahap kedua merupakan tahap pemberian pemahaman mengenai definisi Jurnalis, tugas-tugas dan kemampuan-kemampuan dasar yang wajib dimiliki oleh seorang jurnalis sehingga anak-anak dapat memahami apa saja yang harus dipersiapkan dalam proses mendapatkan informasi, memproses informasi hingga menjadi sebuah berita. Pada sesi ini tim pelaksana melakukan interaksi langsung kepada anak-anak melalui pemahaman Teknik wawancara yang baik dengan merangsang anak-anak untuk berani bercerita dan bertanya tentang apapun.

Tahap ketiga adalah praktek jurnalis anak yang berasal dari pemahaman pada tahap kedua. Pada tahap ini anak-anak mulai diajarkan secara langsung bagaimana membuat informasi menjadi sebuah berita. Anak-anak akan diberikan sebuah note atau kertas dan pulpen dan diminta untuk menceritakan pengalaman menarik mereka yang dapat dijadikan sebuah berita dengan pemahaman yang sudah diberikan pada tahap kedua. Untuk mendapatkan sebuah berita seorang jurnalis harus mengetahui sumber berita (asal muasal / tempat) untuk mengumpulkan fakta menurut Ashadi Siregar dkk (1998), yaitu; Observasi, wawancara, riset komunikasi. Dalam melakukan wawancara, seorang jurnalis harus jeli dalam melihat suatu kejadian agar tidak ada informasi yang terlewat. Seorang jurnalis juga harus melakukan cek lapangan, cek narasumber, cek penulisan berita agar berita yang akan di sebarkan adalah berita yang akurat dan terpercaya. Bahan dan alat yang digunakan dalam kegiatan ini yaitu: 1. Kertas HVS / Noted, 2. Pulpen, 3. Telepon genggam (untuk merekam).

Evaluasi dan monitoring merupakan tahap keempat dan terakhir dari kegiatan Citizen Journalism. Anak-anak diminta untuk mengumpulkan kertas yang berisikan cerita pengalaman yang telah dibuat serta maju satu persatu untuk menjelaskan cerita tersebut dihadapan teman-temannya. Kemudian seluruh hasil karya anak-anak dikumpulkan dan dikoreksi oleh tim pelaksana.

\section{HASIL DAN PEMBAHASAN}

Kegiatan pengabdian kepada masyarakat citizen journalism dengan tema Citizen Journalism: Menjadi Mata dan Telinga bagi Lingkungandimulai dengan tahap pertama berupa perkenalan dan pendekatan diri antara anak-anak dengan tim pelaksana pengabdian dari Universitas Nasional. Anak-anak cukup antusias dan penasaran dengan apaitu jurnalistik, dan seperti apa tugas wartawan. Sebelum memasuki materi, tim pengabdian memberikan pertanyaan kepada anak-anak apa cita-cita mereka. Melalui interaksi seperti ini, satu per satu anak-anak bergiliran menyebutkan cita-cita mereka. Menariknya tidak ada satupun yang bercita-cita menjadi Jurnalis.

Pada tahap kedua, sebelum memasuki pengenalan dan pemahaman jurnalis kepada anak-anak, tim pengabdian lebih dulu memberikan pemahaman mengenai internet, media sosial dan berita hoax. Anak-anak diajak untuk merespon dengan menyebutkan media sosial apa saja yang mereka gunakan, dan seberapa tahu tentang internet. Pada sesi ini diketahui bahwa anak-anak lebih sering menggunakan internet untuk bermain games dan media sosial Instagram. Anak-anak belum pernah menjadi seorang agen informasi yang bermanfaat bagi lingkungan dan orang lain. Setelah sesi pertanyaan, anak-anak diajak 
untuk memahami bahwa menjadi agen informasi berita/kabar positif adalah hal yang baik dan bermanfaat bagi orang lain dan suatu tindakan yang terpuji. Contohnya, jika ada kebanjiran disekitar lingkungan mereka, mereka bisa memberitakan kabar tersebut kepada orang dewasa lain agar dapat melakukan penanggulangan masalah banjir di lingkungan tersebut. Hal ini membuat peserta bersemangat untuk bisa memberikan informasi positif lainnya seperti kebakaran, pencurian, atau berita tentang tempat wisata.

Pada sesi pemahaman diberikan materi tentang apa itu sebuah berita, bagaimana mendapatkan berita, mengolah berita serta cara menyampaikan berita. Pada awalnya anak-anak kurang mengerti, namun setelah diberikan wawasan bahwa informasi untuk mendapatkan sebuah berita dapat diperoleh dari berbagai sumber. Contohnya koran harian, internet, radio, televisi, pengalaman sendiri. Setelah itu melakukan konfirmasi melalui pengamatan panca indera untuk mengecek kebenaran, kepastian, kemudian informasi yang didapat dikumpulkan, disatukan sehingga informasi tersebut siap untuk diolah menjadi sebuah berita. Anak-anak menjadi lebih terbuka hingga memberikan contoh lain bagaimana mendapatkan berita. Hal ini secara tidak langsung membuat anakanak telah menjadi citizen journalism di tempat mereka tinggal. Berikut suasana saat pemberian materi:

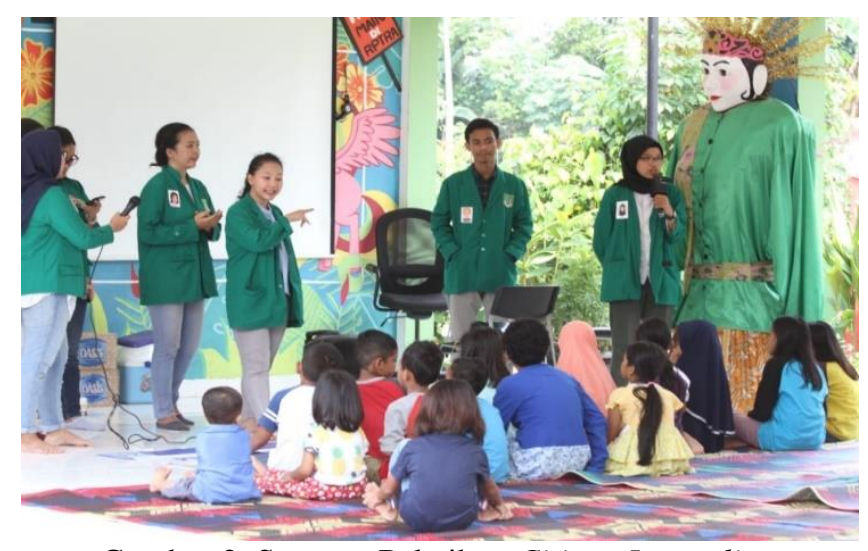

Gambar 2. Suasana Pelatihan Citizen Journalism

Pelatihan ini tidak hanya bertujuan untuk memberikan pemahaman tentang penggunaan internet, media sosial, berita hoax, dan citizen journalism, akan tetapi kegiatan pengabdian kegiatan masyarakat citizen journalism bertujuan untuk bisa mencetak agen-agen informasi yang dapat menjadi mata dan telinga di lingkungan mereka. Oleh sebab itu tim pengabdian kepada masyarakat Universitas Nasional memberikan materi tentang bagaimana mencari sumber informasi, pengolahan informasi, proses informasi menjadi sebuah berita. Mengingat anak-anak baru pertama kali mencoba maka tim pengabdian kepada masyarakat Universitas nasional ikut memandu anak-anak dalam penulisan berita. Anak-anak terlihat bersemangat dalam menuliskan pengalaman pribadi mereka menjadi sebuah berita. Berikutsuasana saat praktek Jurnalis: 


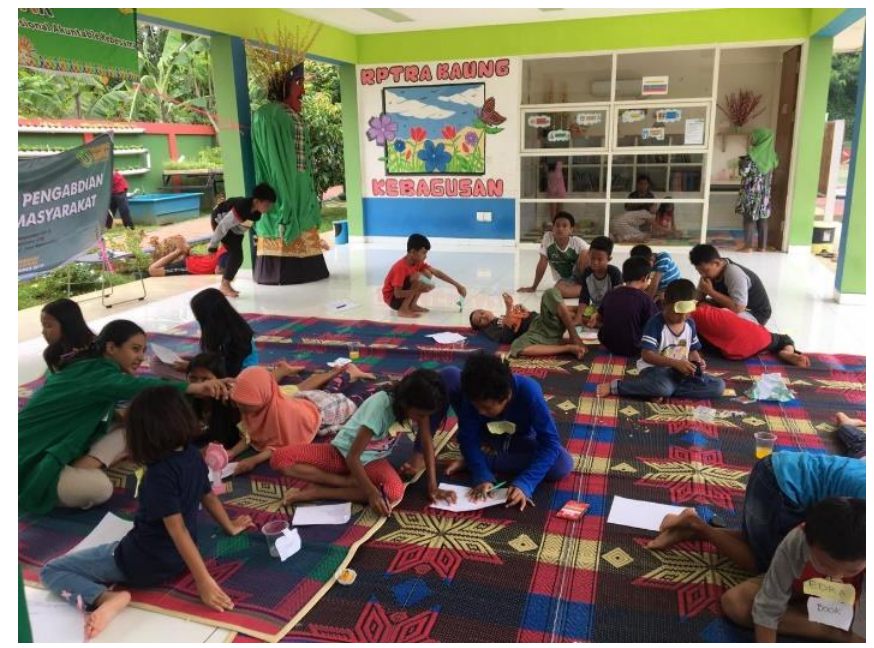

Gambar 3. Anak-Anak mempraktekan menulis pengalaman mereka kedalam sebuah berita.

Pada tahap keempat, anak-anak diminta untuk menceritakan apa yang telah mereka tulis. Seorang anak bernama Fauzan menceritakan pengalamannya bertemu dengan seorang dengan gangguan kejiwaan atau orang gila disekitar lingkungannya. Fauzan memceritakan bahwa orang dengan gangguan kejiwaan tersebut mengganggu temantemannya serta membuat resah lingkungan. Hal ini dilaporkan kepada orang tuanya agar segera mengamankan orang dengan gangguan kejiwaan tersebut. Tim pengabdian kepada masyarakat Universitas Nasional membantu mengevaluasi penulisan pengalaman Fauzan hingga menjadi sebuah berita yang akurat. Anak-anak pada tahap ini mulai diarahkan untuk melakukan wawancara terhadap Fauzan sebagai narasumber. Seperti menanyakan apa yang terjadi, waktu kejadian, tempat kejadian, mengapa terjadi demikian, siapa saja anak-anak yang diganggu, dan bagaimana Fauzan melaporkannya kepada orang dewasa. Dari informasi sederhana ini, anak-anak menjadi tahu bahwa untuk membuat sebuah berita harus memiliki $5 \mathrm{~W}+1 \mathrm{H}$ yaitu what (apa), when (kapan), who (siapa), where (dimana), why (mengapa), dan how (bagaimana). Anak-anak sebagai agen informasi harus berani dan mampu memproses informasi yang dilihat, didengar dan rasakan agar dapat memberitakan informasi tersebut sehingga ketika orang lain mendengar berita itu memberikan perhatian dan kepekaan untuk melakukan suatu tindakan. Berikut suasana saat evaluasi jurnalis:

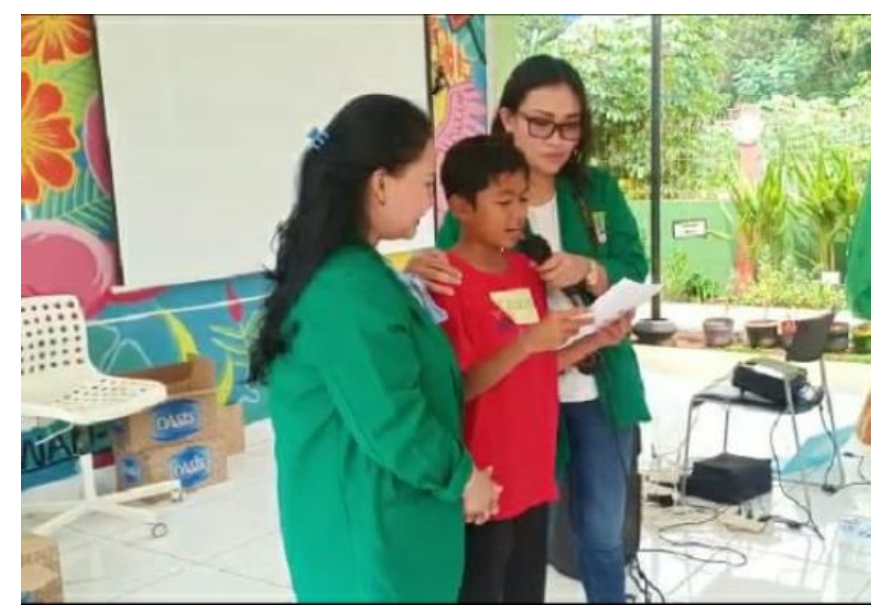

Gambar 4. Anak-anak praktek membacakan berita yang telah dibuat. 
Adapun hasil luaran lain dalam kegiatan pengabdian kepada masyarakat citizen journalism adalah laporan penulisan yang dimuat dimedia online dan dapat diakses di https://m.jpnn.com/news/mahasiswa-prodi-komunikasi-unas-beri-pelatihan-jurnalistikkepada-anak-anak.

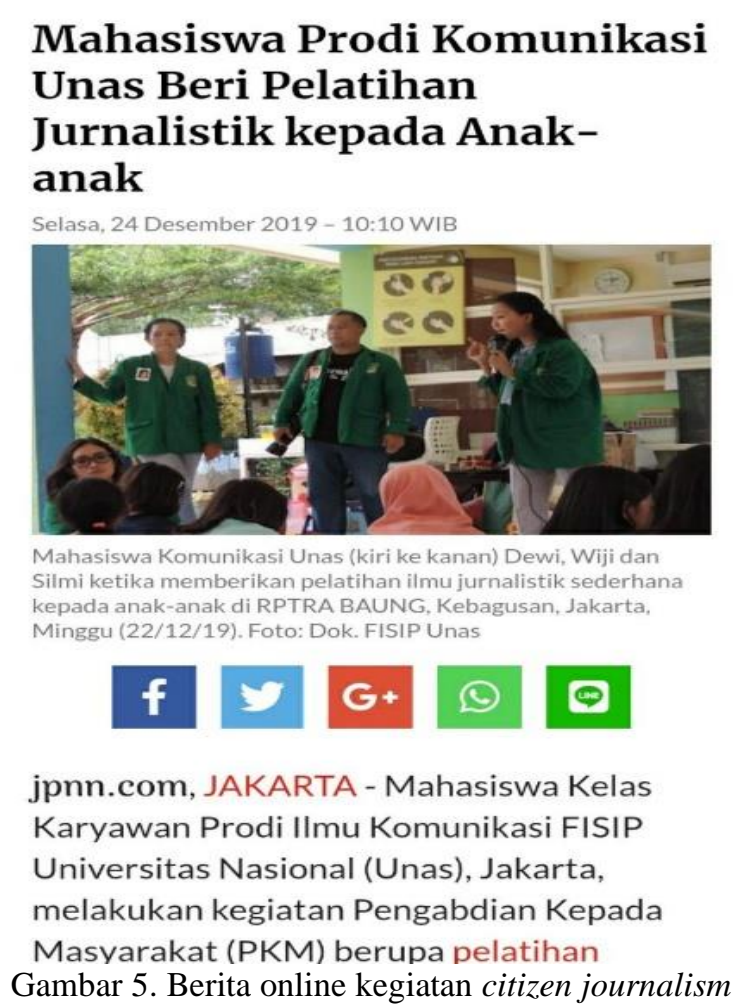

\section{SIMPULAN}

Kegiatan Pengabdian Kepada Masyarakan Universitas Nasional Citizen Journalism berjalan dengan lancar dan sukses. Hal ini dapat dilihat dari antusiasme anak-anak di Ruang Publik Terpadu Ramah Anak (RPTRA) Baung, Jakarta Selatan dalam mengikuti keseluruhan sesi. Dengan menumbuhkan minat baca serta menulis, anak-anak jadi lebih semangat dan menyadari pentingnya membaca dan dampak dari sebuah tulisan. Citizen journalism memberikan pengetahuan baru bagi anak-anak dalam penggunaan internet, media sosial, serta memilah mana berita yang akurat dan berita hoax. Selain itu, anakanak merasa senang dapat menjadi agen informasi, menjadi mata dan telinga dalam menjaga keamanan lingkungan sekitar mereka tinggal. Kegiatan Pengabdian Kepada Masyarakat ini membuat anak-anak memahami pentingnya suatu berita yang akurat agar tidak terjebak dengan berita hoax.

\section{DAFTAR PUSTAKA}

Asosiasi Penyelenggara Jasa Internet Indonesia. (2019). Survey Internet APJII 2018

Caleb T. Carr dan Rebecca A. Hayes (2015), Social Media: Defining, developing, and Divining, atlantic Journal of Communication, Volume 23, 2015

Daryanto, Memahami Kerja Internet, Yrama Widya, Bandung, 2007. 
https://m.jpnn.com/news/mahasiswa-prodi-komunikasi-unas-beri-pelatihan-jurnalistikkepada-anak-anak

Kusumaningati, Imam, 2012. Jadi Jurnalis Gampang, Jakarta: Gramedia

Stark,M., Fins, J.J., \& Stark, M. (2012). The self, social media, and social construction the self, social media, and social construction. The American Journal of Bioethics, 12(10), 37-39. 